\title{
Constant-Frequency Magnetically Controlled Universal Ballast With SoS Compliance for TL5 Fluorescent Lamps
}

\author{
H. V. Marques, Álysson R. Seidel, Member, IEEE, Marina S. Perdigão, Student Member, IEEE, \\ J. Marcos Alonso, Senior Member, IEEE, and E. Sousa Saraiva, Member, IEEE
}

\begin{abstract}
This paper presents the development of a universal electronic ballast for TL5 lamps. The intent is to efficiently operate the maximum number of TL5 lamps with different power ratings at nominal power, using a resonant variable inductance, provided by a magnetic regulator, while maintaining the switching frequency constant. A microcontroller and additional digital circuitry are used to command a dc-dc buck converter to supply the necessary dc control current to the magnetic regulator and to regulate the switching frequency of the half-bridge resonant inverter that supplies the lamp. The selection of the resonant capacitance is done in order to comply with the SoS limits established for each lamp. Experimental results with lamps ranging from 14 to $49 \mathrm{~W}$, operating with high efficiency and high output, are presented in this paper.
\end{abstract}

Index Terms-Electronic ballast, electrode heating, fluorescent lamp, lamp detection, magnetic regulator, resonant circuit, SoS limits, universal ballast, variable inductance.

\section{INTRODUCTION}

$\mathbf{E}$ LECTRONIC ballasts offer greater control because of the inclusion of different power converters in their configuration [1]-[9]. Depending on the complexity of the ballast or the intended installation, they can vary from very simple circuits to more complex circuits involving microprocessors, which is fairly common in commercial solutions [10]. The ability to provide an electronic ballast system capable of driving any lamp

Manuscript received March 9, 2011; revised May 31, 2011; accepted August 3, 2011. Date of current version February 20, 2012. This work was supported in part by the Government of the Portuguese Republic, Fundação para a Ciência e Tecnologia-Ministério da Ciência, Tecnologia e Ensino Superior, under Grant PTDC/EEA-ENE/66859/2006 and Grant SFRH/BD/36143/2007, in part by the Spanish Government, Education and Science Office, under Grant DPI200761267, Grant DPI2010-15889, and Grant DGPU PHB2010-0145-PC, and in part by the Brazilian Government under Grant CAPES/DGU/5267. Recommended for publication by Associate Editor M. Ponce-Silva

H. V. Marques and E. S. Saraiva are with the Instituto de Telecomunicações, Universidade de Coimbra, Coimbra P-3030-290, Portugal (e-mail: heitor_jose@hotmail.com; esaraiva@deec.uc.pt).

Á. R. Seidel is with the Universidade Federal de Santa Maria, CTISM, Santa Maria, Rio Grande do Sul 97105-900, Brazil (e-mail: seidel@ctism.ufsm.br).

M. S. Perdigão is with the Department of Electrical Engineering, Instituto Superior de Engenharia de Coimbra, Coimbra 3030-199, Portugal, and also with the Instituto de Telecomunicações, Universidade de Coimbra, Coimbra P-3030-290, Portugal (e-mail: perdigao@isec.pt).

J. M. Alonso is with the Department of Electrical and Electronics Engineering, Universidad de Oviedo, Gijón 33204, Spain (e-mail: marcos@ieee.org).

Color versions of one or more of the figures in this paper are available online at http://ieeexplore.ieee.org.

Digital Object Identifier 10.1109/TPEL.2011.2165225 within a range of nominal power ratings, thereby guaranteeing the flexibility of the installed lighting system has recently grown in popularity.

The term universal ballast or multiwatt electronic ballast refers to those electronic ballasts that are able to supply different lamps without requiring any physical change in the hardware. In such cases, the ballasts incorporate the necessary intelligence to measure the electrical characteristics of the lamps wired to their output, and are able to adjust their internal operation in order to correctly ignite and supply these lamps, simultaneously guaranteeing safe electrode operation and, consequently, a higher lamp life. From the commercial point of view, these ballasts allow lighting distributors and fixture manufacturers to stock far fewer types of ballasts and this in turn reduce costs [1], [4], [11], [12], [14].

A digitally controlled electronic ballast capable of supplying a set of T8 fluorescent lamps has been proposed in [6]. This ballast is based on a new magnetic control technique. A magnetic regulator, which is a magnetic device with a variable inductance, is used to replace the resonant inductor of the half-bridge resonant inverter that normally drives the lamp. Applications of this control technique were presented in earlier studies [22]-[30]. In this first proposed prototype, in addition to the variable resonant inductance, a second control parameter was used to adapt the power circuit to each lamp: the inverter switching frequency.

In this paper, a prototype for a digitally controlled universal ballast for T5 lamps is proposed. This ballast is capable of supplying tubular fluorescent lamps in the range of 14 to $49 \mathrm{~W}$, high efficiency (HE) series and high output (HO) series. HO lamps deliver more light than standard T5 lamps and are available in higher wattages. The prototype uses the same control technique, yet, in this particular case, the universal ballast will exhibit a constant frequency operation.

Since this ballast is supplied by a dc-bus voltage and because of the relatively high complexity of the proposed converter, a digital control circuit is also developed to control the half-bridge resonant inverter and the buck converter. This buck converter supplies the control windings of the magnetic regulator. In addition, a second converter is used to supply the inverter gate drives and the buck converter. This converter will be connected to the same dc-bus voltage supplying the inverter.

Typically, an important aspect of the design procedure is related to the adequate selection of the operating frequency and the resonant circuit parameters. In order to guarantee safe electrode operation, special attention is given to the selection of 
the resonant capacitance, in order to comply with the sum of squares (SoS) limits established for each selected lamp. These limits are based on the maximum permissible current that may pass through the electrodes. In 2006, these limits were still under discussion at the European Lamp Manufacturers Association for the Preparing of Standards, but, in due time, it was expected that they would result in new data in the relevant IEC standards [12]. These limits are now referenced in the IEC 60081 International Standard (recent edition 2010) and are applicable to other T5 lamps from other manufacturers [13].

This paper will demonstrate that the proposed prototype is capable of supplying almost all available T5 lamps, whether they are $\mathrm{HE}$ or $\mathrm{HO}$.

In Section II, a short review on other universal ballast control techniques together with some considerations on automatic lamp detection methods is provided. In Section III, lamp and topology selections are presented, as well as the control technique. Section IV discusses the design procedure for the resonant tank parameters and Section $\mathrm{V}$ presents the hardware and design configuration. Finally, Sections VI and VII present the experimental results and conclusions, respectively.

\section{Control And LAmp Detection TeChNiQueS IN UNIVERSAL BALLASTS}

\section{A. Control Techniques}

The ability to supply different lamps is based on controlling each lamp current by shifting the operating frequency. However, using the same resonant circuit involves a large range of operating frequencies, which may not be feasible, due to high switching losses and electromagnetic interference (EMI) stresses [1]. This is one of the main reasons why the magnetic regulator control technique was suggested as an efficient alternative. In order to recognize the advantages and simplicity of this type of control, it is important though to recall some of the previous techniques. One of the first methods, presented in [14], suggests adapting the switching frequency and the dc voltage that supplies the resonant converter together, or selectively changing simultaneously both the switching frequency and the duty ratio of the inverter signal. This technique causes an increase in complexity and cost, since another converter with step-up and step-down characteristics is needed. Supplying the lamp with an asymmetrical current waveform, by changing the duty ratio, may also cause premature aging of the lamp.

Another method presented in [18] suggests, after lamp ignition and recognition, to sense its voltage which is then stepped down and modified in order to provide a control signal to determine the switching frequency of the inverter. In order to select and change this switching frequency, a voltage-controlled oscillator and some mapping functions are used.

\section{B. Lamp Detection}

An important issue in universal electronic ballasts is lamp detection. Any mismatch of ballast and lamp power rating may damage the lamp or the electronic ballast. Fluorescent lamp recognition methods have already been addressed and several techniques have been proposed for T12, T8, and T5 lamps [14]-[ 21].

In [19], an automatic lamp detection method is proposed that can differentiate the lamp power of T8 and T12, in the range of 18 to $70 \mathrm{~W}$, by measuring the lamp voltage after the lamp ignition. This was also the method adopted in [6]. With this method, the electronic ballast supplies the lamp at a fixed frequency during the detection period. However, some lamp voltages are similar, and the method may lead to wrong recognition of the lamp.

In order to overcome this drawback, another method that enables the ballast to determine the connected lamp power rating and drive the lamp with proper operating frequency was proposed. This method avoids the mismatch due to lamp voltage overlapping [20]. It presents an automatic lamp detection using lamp power regulation and frequency detection. To ensure that the lamp is recognized correctly, a possibility weight distribution is used. An algorithm is then applied to regulate the power and define the appropriate switching frequency. However, the values of frequency versus lamp power are highly dependent on the resonant components and their deviations. This makes the controller regulate the lamp output power through the operating frequency, which may also result in wrong lamp recognition. In [21], operating frequency and phase shift compensation are used in order to overcome the deviation of the resonant filter components.

In [4], another algorithm for lamp detection and operation for T5, T8, and T12 fluorescent lamps is proposed. A fuzzy logic controller analyzes the heated lamp electrodes, the lamp voltage, and the lamp current. Then, a classification system is generated that maps the lamp characteristics into distinct groups in order to automatically detect each lamp. At the present time, this method seems to be the best alternative.

\section{Proposed Electronic Ballast}

\section{A. Lamp Selection}

T5 fluorescent lamps represent the front line in fluorescent lighting. T5 lamps may be of $\mathrm{HE}$ or $\mathrm{HO}$, and the available power ratings range from 14 to $35 \mathrm{~W}$ for the $\mathrm{HE}$ series, and from 24 to $80 \mathrm{~W}$ for the HO series (Philips) [12]. These lamps are characterized by a high lamp voltage, and in some cases, low current. This is the reason why they are conventionally manufactured for high-frequency operation. Due to their smaller diameter, compared to conventional tubular lamps, they need less material, which means lower construction costs. They are also environmental friendly because they have less mercury. Given their smaller volume and that they achieve maximum light output at temperatures around $35{ }^{\circ} \mathrm{C}$, which is a normal temperature in luminaries, T5 lamps allow the development of lighting systems where space limitations are a major concern.

\section{B. Topology Selection and Control Technique}

Each TL5 lamp is supplied by a voltage-fed resonant inverter connected to a parallel-loaded resonant circuit, as shown in 


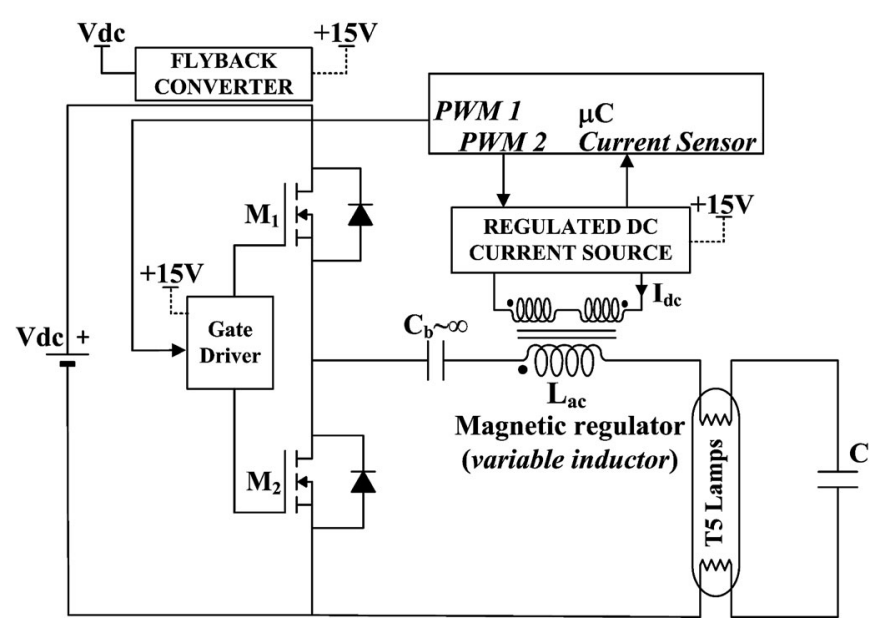

Fig. 1. Schematic of the proposed electronic ballast.

Fig. 1. In order to function properly, the ballast requires two additional $\mathrm{dc}-\mathrm{dc}$ converters and a microcontroller unit microcoulomb. The two bidirectional switches and the dc voltage source $V_{\mathrm{dc}}$ provide a square-wave voltage source that drives the resonant circuit formed by the magnetic regulator, with the variable inductance $L_{\mathrm{ac}}$, the resonant capacitor $C$, and the fluorescent lamp. If the quality factor of this resonant circuit $Q$ is sufficiently high, the resonant current will be nearly sinusoidal. For this ballast, the rms value of the lamp voltage can be obtained using [31]

$$
V_{\text {lamp }}=V_{\text {in }} \frac{1}{\sqrt{\left(1-\omega^{2} L_{\mathrm{ac}} C\right)^{2}+\left(\omega L_{\mathrm{ac}} / R_{\mathrm{lamp}}\right)^{2}}}
$$

where $V_{\text {in }}$ is the rms value of the fundamental component of the resonant-circuit input voltage after a dc-blocking capacitor $C_{b}$. This dc-blocking capacitor, which will have a high value, is necessary in order to prevent dc current value to flow through the lamp. The presence of this a current would easily damage the electrodes and reduce lamp life. If a lower value of $C_{b}$ is used, it must be included as a design parameter and the behavior of the circuit would no longer be that of an $L C$ circuit but instead that of an $L C C$ circuit. Both configurations are used in ballast circuits; however, the $L C$ circuit configuration is simpler.

Taking into account (1), the output lamp power can be defined as

$$
P_{\text {lamp }}=\frac{V_{\text {lamp }}^{2}}{R_{\text {lamp }}}=V_{\text {in }}^{2} \frac{R_{\text {lamp }}}{P_{\text {lamp }}^{2}\left(1-\omega^{2} L_{\mathrm{ac}} C\right)+\left(\omega L_{\mathrm{ac}}\right)^{2}}
$$

where $V_{\text {in }}=4\left(\left(V_{\mathrm{dc}} / 2\right) /(\pi \sqrt{2})\right)=(\sqrt{2} / \pi) V_{\mathrm{dc}}$.

The analysis of the lamp power equation shows that if the inverter is operated at a constant switching frequency, and if the capacitor value remains constant, it is possible to control the delivered power by simply adjusting the inductance value, $L_{\mathrm{ac}}$. Contrary to previously presented solutions, where the delivered power was controlled by two different parameters, typically the switching frequency and another control variable, this ballast is capable of controlling several lamps using only one parameter [5], [17], [18].
The ballast operating procedure will be as follows: after the lamp recognition, a control current is delivered to the magnetic regulator which will then change its inductance according to the estimated value for the attached lamp. This control current is supplied by a regulated dc-current source, a dc-dc buck converter working in continuous conduction mode. In fact, the variation of the inductance is imposed by the dc current $I_{\mathrm{dc}}$ that is supplied to the control windings of the magnetic regulator. The microcontroller is also able to measure the dc current. The control of $I_{\mathrm{dc}}$ is done by adjusting the duty cycle of a pulsewidth modulation (PWM) signal, generated by the microcontroller and applied to the converter, according to a voltage reference $V_{\text {ref }}$. This voltage reference can be imposed manually, or by the microcontroller according to the implemented lamp detection method. Based on the methodology presented in [4], this voltage reference would be defined according to the results obtained from the application of the fuzzy logic algorithm proposed in [4].

As shown in Fig. 1, the necessary voltage for both gate driver and buck converter, $15 \mathrm{~V}$, is generated by a dc-dc flyback converter supplied by the ballast dc-bus voltage $V_{\mathrm{dc}}$. The ballast circuit is supplied by a dc voltage source $V_{\mathrm{dc}}$ of $310 \mathrm{~V}$. The flyback converter ensures electrical isolation between the power stage and the control stage of the ballast, which is also guaranteed by two optocouplers, one used in the dc-dc buck converter and the other in the gate driver. The gate driver, responsible for setting the half-bridge inverter switching frequency $f_{s}$, is also managed by the microcontroller, during the preheating mode and at steady-state conditions. The generated PWM signal will have a duty cycle of approximately $50 \%$ for an even aging of the lamp electrodes. A comprehensive ballast schematic is further shown in Fig. 12 and additional details on the magnetic regulator are presented in Section IV-D.

\section{Resonant CiRCUIT DESIGN}

\section{A. Standard Design Procedure}

The primary goal is to operate different TL5 lamps at nominal power while maintaining the same switching frequency $f_{s}$ and the same resonant circuit capacitance. So, it is necessary to calculate the capacitance and the inductance values required by each lamp. As a first step, the criteria presented in [31] are used to obtain the main parameters of the resonant circuit. For the halfbridge inverter connected to a parallel-loaded resonant tank, the maximum voltage gain can be approximated by $Q$ at the natural frequency $f_{o}, Q$ being the normalized load, as represented in (4). This equation can be used to calculate the base impedance of each resonant circuit $Z_{b}$, for each lamp, using the nominal values for the lamp voltage $V_{\text {lamp }}$, and the lamp resistance $R_{\text {lamp }}$. So, as a first step, the estimation of the resonant filter parameters, $L_{\mathrm{ac}}$ and $C$, is done considering that $f_{s}=f_{o}$. Therefore, if the desired operating frequency for the lamps $f_{s}$ is selected, (3)-(5) can be used to estimate the values for $L_{\mathrm{ac}}$ and $C$

$$
V_{\mathrm{in}}=\frac{4 \cdot\left(V_{\mathrm{dc}} / 2\right)}{\pi \cdot \sqrt{2}}=\frac{\sqrt{2}}{\pi} V_{\mathrm{dc}}
$$


TABLE I

CAPACITANCE AND INDUCTANCE THEORETICAL VALUES

\begin{tabular}{ccc}
\hline \hline Lamp & $\boldsymbol{C}$ [nF] & $\boldsymbol{L}_{\boldsymbol{a c}}[\mathbf{m H}]$ \\
\hline \hline TL5 HE series $(14 / 21 / 28 / 35)$ & 3.48 & 2.35 \\
\hline TL5 HO24W & 6.15 & 1.33 \\
\hline TL5 HO39W & 6.94 & 1.17 \\
\hline TL5 HO49W & 5.33 & 1.53 \\
\hline \hline
\end{tabular}

$$
\begin{aligned}
Q & =\frac{V_{\text {lamp }}}{V_{\text {in }}}=\frac{R_{\text {lamp }}}{Z_{b}}, \quad \text { for } f_{s}=f_{o} \\
Z_{b} & =\sqrt{\frac{L}{C}}, \quad \text { for } f_{s}=f_{o} \\
L_{\mathrm{ac}} & =\frac{Z_{b}}{2 \pi f_{o}} \\
C & =\frac{1}{2 \pi Z_{b} f_{o}} .
\end{aligned}
$$

The rms value of the lamp discharge or arc current $I_{D}$ can be defined as

$$
I_{D}=\frac{V_{\text {lamp }}}{R_{\text {lamp }}}
$$

It implies that if the circuit is operated at $f_{s}=f_{o},(8)$ can be rewritten as follows:

$$
I_{D}=\frac{V_{\text {lamp }}}{R_{\text {lamp }}}=\frac{V_{\text {in }} Q}{R_{\text {lamp }}}=\frac{V_{\text {in }}}{Z_{b}} .
$$

Therefore, the circuit will behave as a current source, and its value depends exclusively on the input voltage and $Z_{b}$. Taking into account the preceding considerations, the capacitance and inductance values for the selected lamps may be calculated, respectively, by rewriting (6) and (7)

$$
\begin{aligned}
L_{\mathrm{ac}} & =\frac{V_{\mathrm{in}}}{2 \cdot \pi \cdot f_{s} \cdot I_{D}} \\
C & =\frac{I_{D}}{2 \cdot \pi \cdot f_{s} \cdot V_{\mathrm{in}}} .
\end{aligned}
$$

For this prototype, the input dc voltage was set at $V_{\mathrm{dc}}=310 \mathrm{~V}$ and the switching frequency at $f_{s}=55 \mathrm{kHz}$. The estimated parameters for each lamp are presented in Table I.

According to Table I, the resonant capacitor varies according to each type of lamp. However, this capacitance must remain constant in the resonant circuit. A capacitor of $4.7 \mathrm{nF}$ was initially selected, as an average value, for the HE series and the HO series, and also for being a typical commercial value between the obtained limits.

\section{B. Conditions to Obtain Zero Voltage Switching (ZVS)}

According to [7], when $Q<1$, the resonant frequency $f_{r}$ does not exist and the circuit operates as an inductive load at any $f_{s}$. If $Q \geq 1$, and $f_{s}>f_{r}$, then the switches are loaded by an inductive load. In both situations, ZVS is achieved, since the resonant current lags the inverter output voltage.
TABLE II

$Q, f_{r}$, AND $f_{o}$ VALUES With a SingLe 4.7- $n$ F Capacitor

\begin{tabular}{cccc}
\hline \hline Lamp & $\boldsymbol{Q}$ & $\boldsymbol{f}_{\boldsymbol{o}}[\mathbf{k H z}]$ & $\boldsymbol{f}_{\boldsymbol{r}}[\mathbf{k H z}]$ \\
\hline \hline TL5 HE14W & 0.683 & 47.93 & - \\
\hline TL5 HE 21W & 1.024 & 47.93 & 10.36 \\
\hline TL5 HE 28W & 1.391 & 47.93 & 33.31 \\
\hline TL5 HE 35W & 1.74 & 47.93 & 39.23 \\
\hline TL5 HO24W & 0.47 & 63.68 & - \\
\hline TL5 HO39W & 0.659 & 67.79 & - \\
\hline TL5 HO49W & 1.286 & 59.28 & 37.27 \\
\hline \hline
\end{tabular}

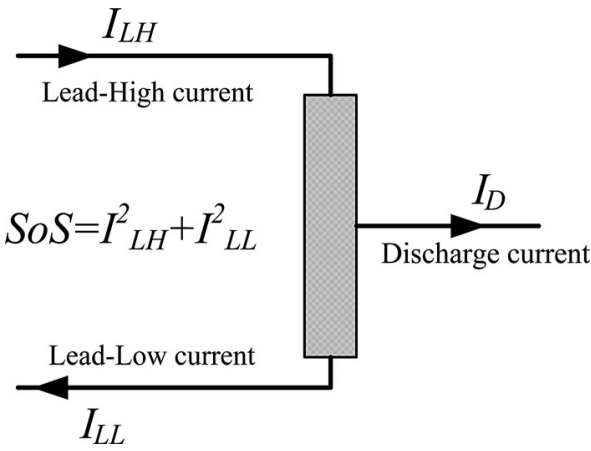

Fig. 2. Lamp electrode currents definition.

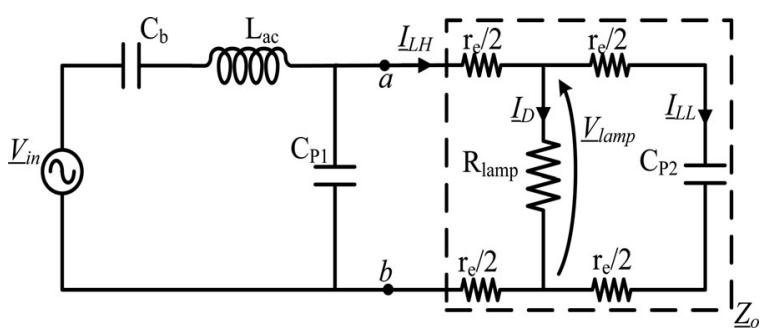

Fig. 3. Equivalent circuit.

When $Q \geq 1$, the resonant frequency is given by the following equation:

$$
f_{r}=f_{o} \cdot \sqrt{1-\frac{1}{Q^{2}}}, \quad f_{o}=\frac{1}{2 \pi \sqrt{L C}}
$$

Considering the selected capacitor value and assuming the same inductance values for each lamp, the recalculation of the $f_{o}$ and $Q$ for each resonant circuit shows that $Q$ is below 1 for the HE $14 \mathrm{~W}, \mathrm{HO} 24 \mathrm{~W}$, and $\mathrm{HO} 39 \mathrm{~W}$, thereby behaving as an inductive load, whereas for the remaining lamps the circuit is resonant. This can be seen in Table II. So, under these conditions, the inverter will operate with ZVS.

Nonetheless, according to [12], the lifetime of a fluorescent lamp is determined by the lifetime of the electrodes and their temperature must be kept within certain limits. If they are too hot, enhanced evaporation of the emissive material and severe end blackening will take place. If they are too cold, sputtering of the emitter will occur [6], [12]. Both situations lead to significantly reduced lifespan of the lamp. This is the reason why it is also important to verify if the selected capacitor value guarantees safe electrode operation, by verifying compliance with the 
TABLE II

Lamp Voltage, Discharge CuRRent, Electrode Resistance, AND SOS LIMITS

\begin{tabular}{|c|c|c|c|c|c|}
\hline Lamp & $V_{\text {lamp }}[\mathbf{V}]$ & $I_{D}[\mathrm{~mA}]$ & $\begin{array}{l}\boldsymbol{r}_{e} \\
{[\boldsymbol{\Omega}]} \\
\end{array}$ & $\begin{array}{c}I_{L H \max } \\
{[\mathrm{mA}]} \\
\end{array}$ & $\begin{array}{l}I_{L L \max } \\
{[\mathrm{mA}]} \\
\end{array}$ \\
\hline TL5 HE14W & $82 \pm 10$ & $170 \pm 40$ & 40 & 240 & 170 \\
\hline TL5 HE21W & $123 \pm 10$ & $170 \pm 40$ & 40 & 240 & 170 \\
\hline TL5 HE28W & $167 \pm 17$ & $170 \pm 40$ & 40 & 240 & 170 \\
\hline TL5 HE35W & $209 \pm 20$ & $170 \pm 40$ & 40 & 240 & 170 \\
\hline TL5 HO24W & $75 \pm 8$ & $300 \pm 30$ & 12 & 475 & 370 \\
\hline TL5 HO39W & $112 \pm 10$ & $340 \pm 70$ & 12 & 475 & 370 \\
\hline TL5 HO49W & $191 \pm 20$ & $260 \pm 50$ & 16.5 & 370 & 275 \\
\hline
\end{tabular}

established SoS limits. In [14], for instance, a study on the SoS limits was considered in the design of an LCC resonant filter for dimming a T8/32W lamp using frequency control.

\section{Capacitance Selection Based on the SoS Limits}

The temperature of the electrodes is primarily influenced by the three currents represented in Fig. 2.

One way to evaluate the conditions for proper operation of the electrodes is based on the SOS definition

$$
\mathrm{SoS}=I_{L H}^{2}+I_{L L}^{2} ; I_{L H}>I_{L L} .
$$

The currents $I_{L H}$ and $I_{L L}$ have been measured with a current probe around the lead in wire. The higher one is named $I_{L H}$ and the lower one named $I_{L L}$. By taking both lead in wires together through a current probe, $I_{D}$ can be measured. As will be demonstrated, a capacitor value of $4.7 \mathrm{nF}$ will not obey the SoS limits presented in Table III, as retrieved from [12].

In order to obey these limits, a dual capacitor configuration is implemented. The parallel capacitance of the resonant filter $C$ is split into two capacitances, $C_{P 1}$ and $C_{P 2}$, as shown in Fig. 3. These capacitors must be designed for the worst case, which is defined as a lamp that has the minimum values for $I_{L H \text { max }}$ and $I_{L L \max }$ and the highest lamp voltage. As shown in Table III, the minimum values for $I_{L L}$ and $I_{L H}$ correspond to the TL5 HE series, and the HE $35 \mathrm{~W}$ presents the highest lamp voltage. The required inductance value will not be affected by the selection of a different resonant capacitor value, so, through both analyses, the inductances are assumed to be the initial values, as defined in Table I.

Thus, $C_{P 2}$ is limited by the minimum $I_{L L}$ current and the highest lamp voltage. These two values establish the maximum value for $C_{P 2}$ as defined by (14), where $r_{e}$ corresponds to the electrode resistance [10]

$$
\left|\underline{V}_{\text {lamp }}\right|=\left|\underline{I}_{L L}\right| \cdot\left|\frac{1}{j \omega_{s} C_{P 2}}+r_{e}\right| .
$$

According to Table III, the rated heated electrode resistance for the HE series is $40 \Omega$ and the nominal lamp voltage for the HE $35 \mathrm{~W}$ lamp is $209 \mathrm{~V}$. So, taking into consideration that $\left(1 / \omega_{s} C_{P 2}\right) \gg r_{e}$, a $2.2 \mathrm{nF}$ capacitor was selected.

$C_{P 1}$ is calculated to obey the lowest maximum admissible value for the $I_{L H}$ current, which is determined by the HE series.

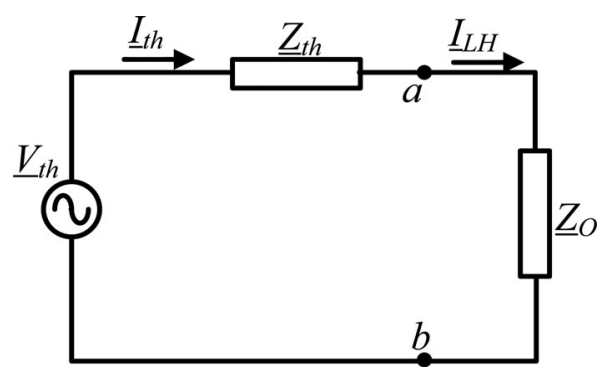

Fig. 4. Thévenin's equivalent circuit.

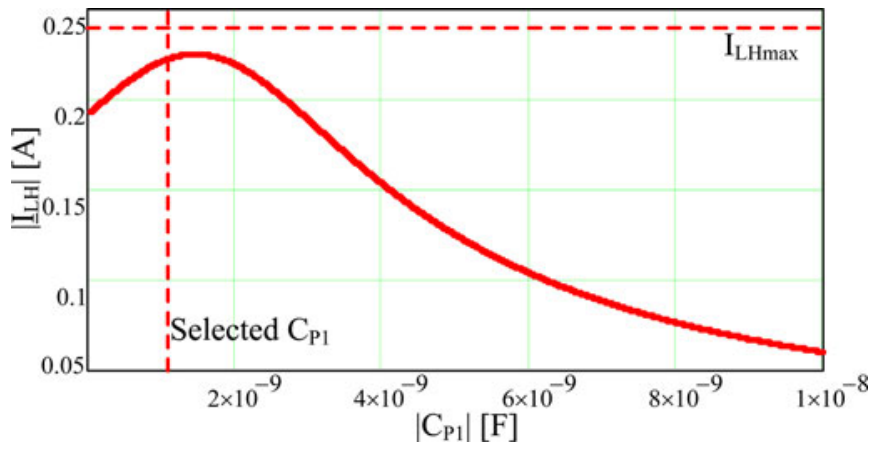

Fig. 5. Variation of $I_{L H}$ as a function of $C_{P 1}$.

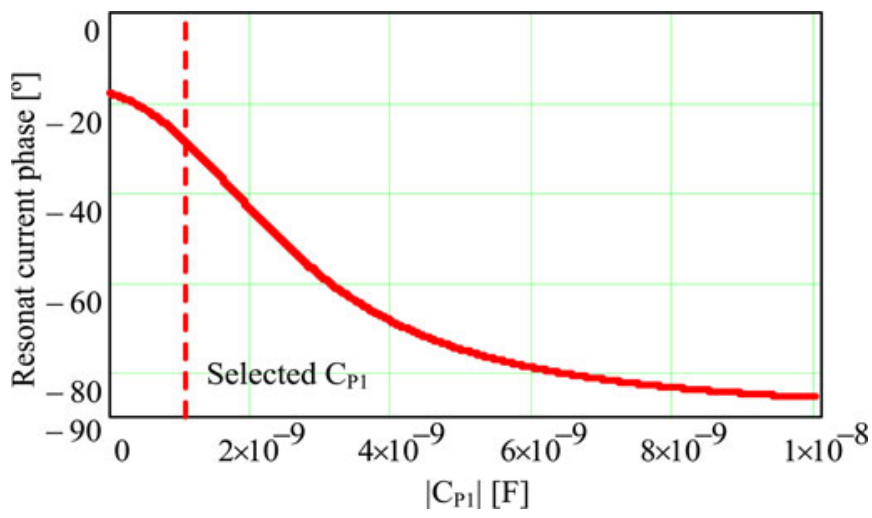

Fig. 6. Variation of the resonant current phase as a function of $C_{P 1}$.

This current can be determined by Thévenin's theorem applied to the $a$ and $b$ terminals as shown in Fig. 4 .

From Fig. 4, the following equations can be established

$$
\begin{aligned}
\underline{Z}_{O} & =\frac{\left(r_{e}+\left(1 / j \omega_{s} C_{P 2}\right)\right) \cdot R_{\mathrm{lamp}}}{R_{\mathrm{amp}}+r_{e}+\left(1 / j \omega_{s} C_{P 2}\right)}+r_{e} \\
\underline{Z}_{\mathrm{th}} & =\frac{\left(\left(1 / j \omega_{s} C_{b}\right)+j \omega_{s} L_{\mathrm{ac}}\right) \cdot\left(1 / j \omega_{s} C_{P 1}\right)}{\left(1 / j \omega_{s} C_{b}\right)+\left(1 / j \omega_{s} C_{P 1}\right)+j \omega_{s} L_{\mathrm{ac}}} \\
\underline{V}_{\mathrm{th}} & =\frac{\left(1 / j \omega_{s} C_{P 1}\right)}{\left(1 / j \omega_{s} C_{b}\right)+\left(1 / j \omega_{s} C_{P 1}\right)+j \omega_{s} L_{\mathrm{ac}}} \cdot \underline{V}_{S}
\end{aligned}
$$

where $\underline{Z}_{O}$ is the load impedance, obtained by the combination of the lamp resistance, electrode resistance, and $C_{P 2} ; \underline{Z}_{\text {th }}$ and $\underline{V}_{\mathrm{th}}$ are Thévenin's equivalent impedance and voltage. Finally, the current $\underline{Z}_{\text {th }}$ can be determined by

$$
\underline{I}_{\mathrm{th}}=\underline{I}_{L H}=\frac{\underline{V}_{\mathrm{th}}}{\underline{Z}_{\mathrm{th}}+\underline{Z}_{O}} .
$$


TABLE IV

$Q, f_{r}$, and $f_{o}$ Values With a Capacitance of $3.3 \mathrm{nF}$

\begin{tabular}{cccc}
\hline \hline Lamp & $\boldsymbol{Q}$ & $\boldsymbol{f}_{\boldsymbol{o}}[\mathbf{k H z}]$ & $\boldsymbol{f}_{\boldsymbol{r}}[\mathbf{k H z}]$ \\
\hline \hline TL5 HE14W & 0.572 & 57.21 & - \\
\hline TL5 HE 21W & 0.858 & 57.21 & - \\
\hline TL5 HE 28W & 1.165 & 57.21 & 29.36 \\
\hline TL5 HE 35W & 1.458 & 57.21 & 41.64 \\
\hline TL5 HO24W & 0.394 & 75.99 & - \\
\hline TL5 HO39W & 0.553 & 80.9 & - \\
\hline TL5 HO49W & 1.078 & 70.75 & 26.36 \\
\hline \hline
\end{tabular}

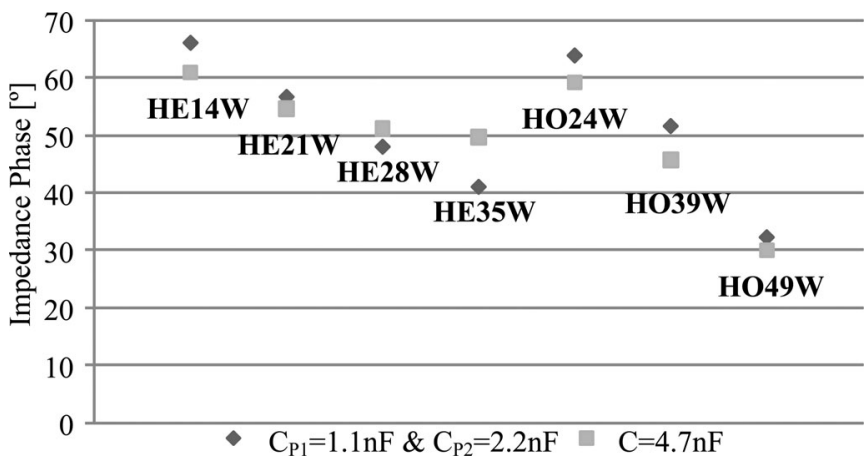

Fig. 7. Impedance phase angle for each TL5 lamp at $f_{s}$.

The impedance of the circuit can be determined as follows:

$$
\underline{Z}=\frac{1}{j \omega_{s} C_{b}}+j \omega_{s} L+\frac{\underline{Z}_{O} \cdot\left(1 / j \omega_{s} C_{P 1}\right)}{\underline{Z}_{O}+\left(1 / j \omega_{s} C_{P 1}\right)} .
$$

Figs. 5 and 6 show, respectively, the plot of $\left|\underline{I}_{L H}\right|$ and the plot of the resonant current phase, both as function of $C_{P 1}$. It is noted that the resonant current phase is equal to the phase of the input admittance $1 / \underline{Z}$. These plots assume $C_{P 2}$ at the previously determined value, $2.2 \mathrm{nF}, R_{\text {lamp }}$ at the rated values of voltage and current for the HE $35 \mathrm{~W}$ lamp, $L_{\mathrm{ac}}$ as calculated in (10), and $C_{b}$ at $1 \mu \mathrm{F}$.

From the analysis of Figs. 5 and 6, $C_{P 1}$ can take any of several values, because the $I_{L H \text { max }}$ will not be reached. The necessary lag between the resonant current and the inverter output voltage will not be risked.

An initial value of $2.2 \mathrm{nF}$ was selected for $C_{P 1}$. In these conditions, the equivalent parallel resonant capacitance, $C_{\text {peq }}=$ $C_{P 1}+C_{P 2}$, would be near $4.7 \mathrm{nF}$. However, experimental results showed that with this configuration, the HE $35 \mathrm{~W}$ lamp was submitted to voltage oscillations. Since the damping factor for this circuit was the lowest of all, by decreasing $C_{P 1}$ it was possible to eliminate this drawback. So, a capacitor of $1.1 \mathrm{nF}$ was finally selected.

Since the equivalent parallel resonant capacitance is lower than the initial selected value, $4.7 \mathrm{nF}$, it is obvious that the natural frequencies will shift from the values defined in Table III. The new set of values for the normalized load, natural and resonant frequency, considering the sum of $C_{P 2}$ and $C_{P 1}$, is presented in Table IV.
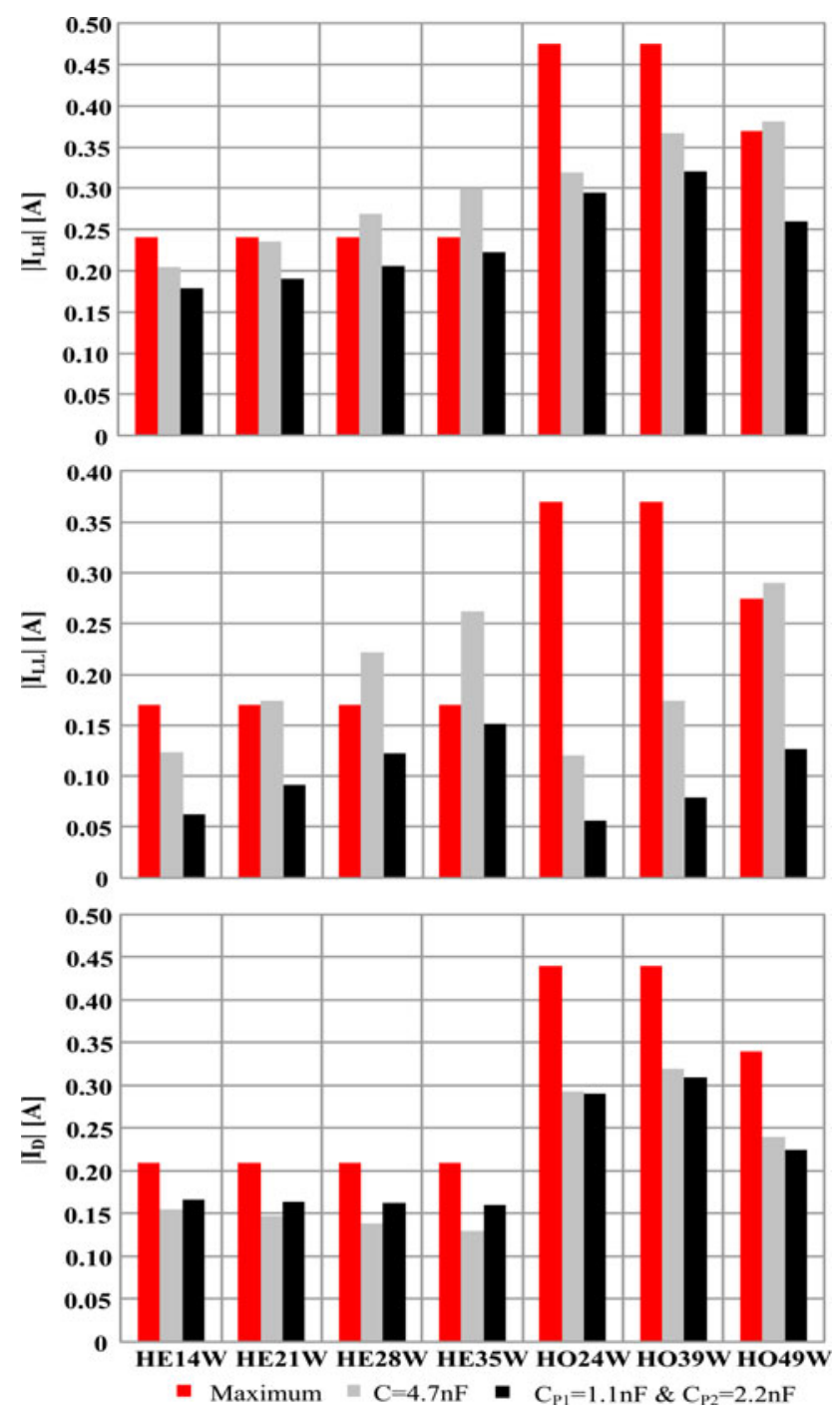

Fig. 8. $I_{L H}, I_{L L}$, and $I_{D}$ currents considering both capacitor configurations.

As can be seen, with this configuration, when compared to Table II, the circuit also ceases to be resonant for the HE $21 \mathrm{~W}$ lamp. However, it still behaves as an inductive load.

Figs. 7 and 8 present a final comparison between both solutions: using a single capacitor or the dual capacitor configuration. Fig. 7 compares the impedance phase angle of the resonant tank for both capacitor configurations, using (19). Since the resonant circuit remains with a positive impedance phase angle with all the selected lamps, ZVS operation is guaranteed in all situations, because the resonant current still lags from the inverter voltage output.

Fig. 8 clearly shows how the single capacitor configuration imposes excessive current to the electrodes, especially with the HE series. This would lead to quicker degradation over time. On the other hand, the dual capacitor configuration significantly counteracts the results obtained with the initial configuration. All the currents considered are now below their permissible limit. 


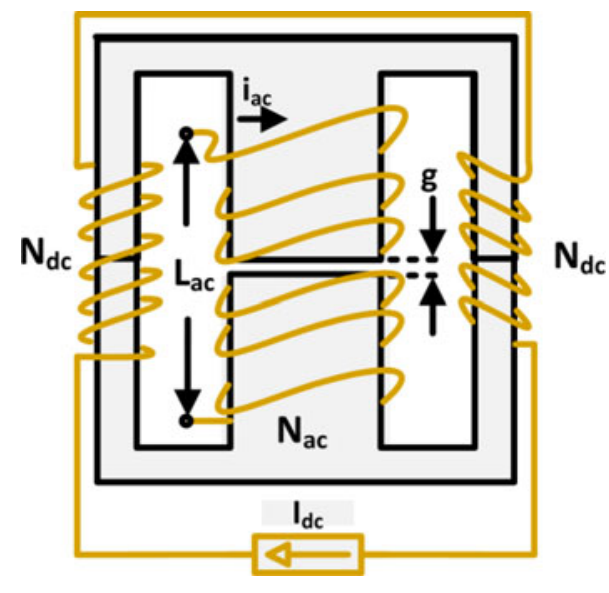

Fig. 9. Structure of the magnetic regulator and prototype.

\section{Magnetic Regulator}

The working principle of this device is to control its main inductance value through the variation of the permeance in different regions of the core. This implies that the $B(H)$ curve of the magnetic material is nonlinear. The selected magnetic regulator structure is presented in Fig. 9. The winding $N_{2}$, placed in the central leg of the core, corresponds to the variable inductance winding, defining its initial value. Both $N_{1}$ and $N_{3}$ windings are assembled on the side legs of the core. When a dc control current is flowing through them, it will generate two magnetomotive forces, which will allow the variation of the initial $L_{\mathrm{ac}}$ value. The maximum value of inductance $L_{\mathrm{ac}}$ is obtained for a zero dc control current $I_{\mathrm{dc}}$. As the current is increased, $L_{\mathrm{ac}}$ decreases due to saturation. Given the nonlinearity of the magnetic material, a nonlinear coupling between the ac winding and the control windings is still present, even if the control windings are symmetrical.

\section{EXPERIMENTAL PROTOTYPE}

Fig. 10 shows the implemented circuit for the voltage-fed resonant ballast. The main driver, IR2111, is responsible for the command of the half-bridge inverter. Since the supply voltage of the IR2111 driver is $15 \mathrm{~V}$, the amplitude of the PWM signal generated by the microcontroller has to be adapted for the driver to work properly. This is accomplished using a HCLP3120 driver, which grants electrical isolation from the power stage. A digital 16-bit PWM, PWM1, as previously shown in Fig. 1, is applied to the gate driver in order to establish the inverter switching frequency $f_{s}$ at $55 \mathrm{kHz}$ according to the selected value. This PWM signal is generated by a programmable system-on-chip CY8C29446.

As mentioned previously, in order to block the dc component of the input voltage of the filter, capacitor $C_{b}$ is chosen to be $1 \mu \mathrm{F}$. $C_{P 2}$ is selected according to (14), which imposes a $2.2 \mathrm{nF}$ capacitor value, and $C_{P 1}$ is selected according to the theoretical analysis exposed in Section IV-C, which determines a $1.1 \mathrm{nF}$ capacitor value. With these capacitances, all SoS limits will be obeyed.
TABLE V

$V_{\text {lamp }}$ AND $I_{D}$ ACHIEVED FOR EACH LAMP

\begin{tabular}{ccc}
\hline \hline Lamp & $\boldsymbol{V}_{\text {lamp }}[\mathbf{V}]$ & $\boldsymbol{I}_{\boldsymbol{D}}[\mathbf{A}]$ \\
\hline \hline HE14W & 88.02 & 0.1609 \\
\hline HE21W & 129.2 & 0.1656 \\
\hline HE28W & 175.6 & 0.1618 \\
\hline HE35W & 219.5 & 0.1602 \\
\hline HO24W & 79.55 & 0.306 \\
\hline HO39W & 122.9 & 0.3187 \\
\hline HO49W & 223.7 & 0.1953 \\
\hline \hline
\end{tabular}

The design of the magnetic regulator was based on the methodology presented in [5] and according to the required inductance values estimated for each lamp, as shown in Table I. This design procedure was followed considering that this inductor should have a broad inductance range, in order to cover the estimated inductance range. According to the values presented in Table I, the magnetic regulator must have as a minimum an inductance variation between 1 and $2.5 \mathrm{mH}$, approximately. A magnetic regulator prototype was built using two EFD20/10/7 cores, with $\mathrm{N} 87$ type core material. The built prototype and the small-signal characteristic of the magnetic regulator, for a dc control current of $0-1 \mathrm{~A}$, are both presented in Fig. 11. The main winding $N_{a c}$ is composed of 150 turns while the control windings $N_{d c}$ are 55 turns each. The gap in the main winding is $0.25 \mathrm{~mm}$. The small-signal characteristic was obtained using a $L C R$ meter, BK Precision 899A, which applies a small signal to the main winding of $1 \mathrm{~V} / 100 \mathrm{kHz}$. In Fig. 10 , the $R C$ circuit placed in parallel with the main inductance of the magnetic regulator is used to estimate the large-signal inductance for each lamp.

Fig. 12 shows the implemented dc-dc buck converter. Its output is adjusted to supply a maximum of $1 \mathrm{~A}$ of current in continuous conduction mode. The PWM signal is set at $100 \mathrm{kHz}$ and the variation of the duty cycle is imposed by the voltage reference $V_{\text {ref }}$, which has a variation of 0 to $5 \mathrm{~V}$. In the presented prototype, this voltage reference is externally controlled, but in the future this voltage reference will be dependent on the implemented lamp detection routine. This routine must identify the lamp and must be able to manage the buck converter operating duty cycle. This duty cycle dictates the level of dc current flowing though the control windings of the magnetic regulator, setting its inductance value to the appropriate level in order to operate each lamp at its rated power. The microcontroller is also configured and programmed to measure the dc current that passes through the control windings of the magnetic regulator, through an incremental A/D converter of 10-bit resolution.

An HCPL3120 optocoupler is used to provide electrical isolation to the control stage from the power stage. The diode D2 is used to block any induced ac voltage from the magnetic regulator due to asymmetries in the construction of the magnetic regulator, and due to the magnetic nonlinearity coupling.

The flyback converter employs the integrated circuit, IC, VIPer 50A. This IC combines on the same chip a PWM circuit with a vertical power MOSFET (700 V/1.5 A/5.7 $\Omega$ ) working in discontinuous conduction mode. The design of this converter 


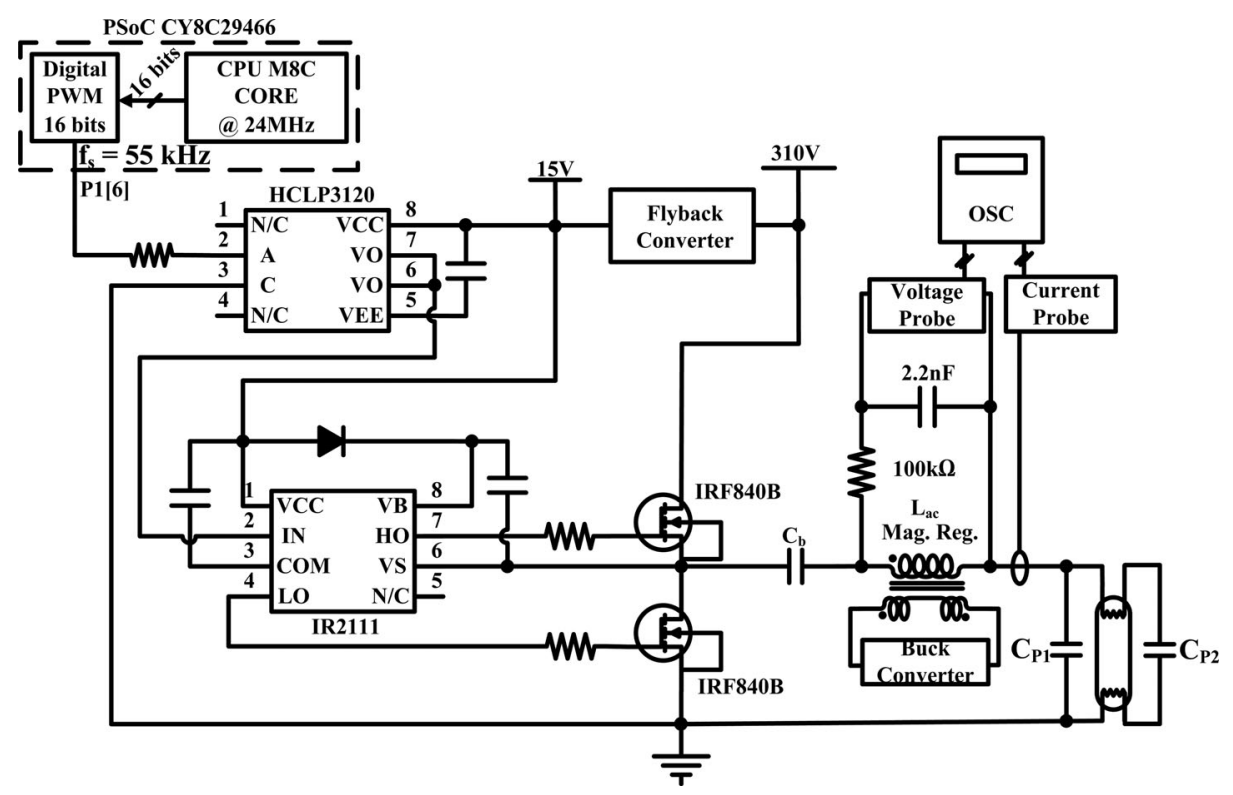

Fig. 10. Schematic of the voltage-fed resonant ballast.
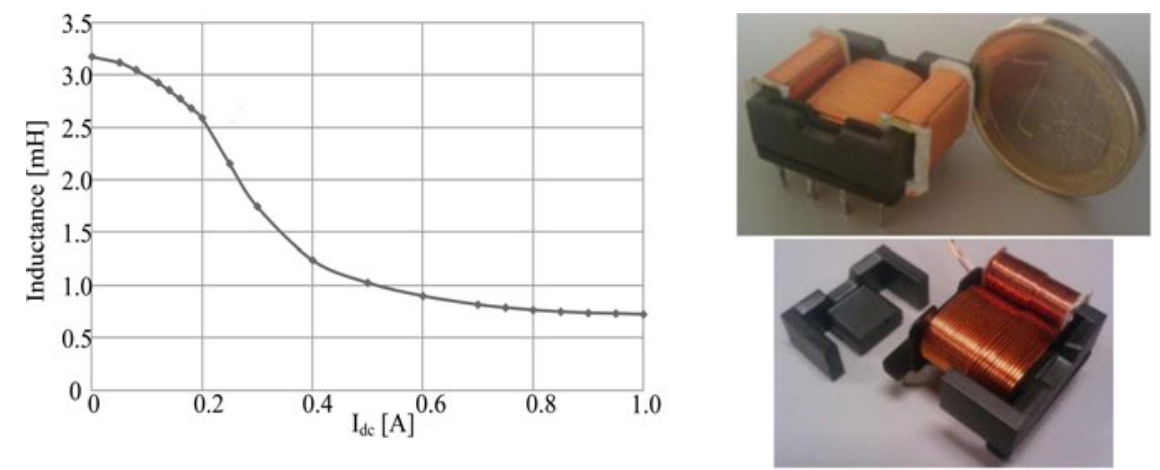

Fig. 11. Small-signal characterization of the magnetic regulator.

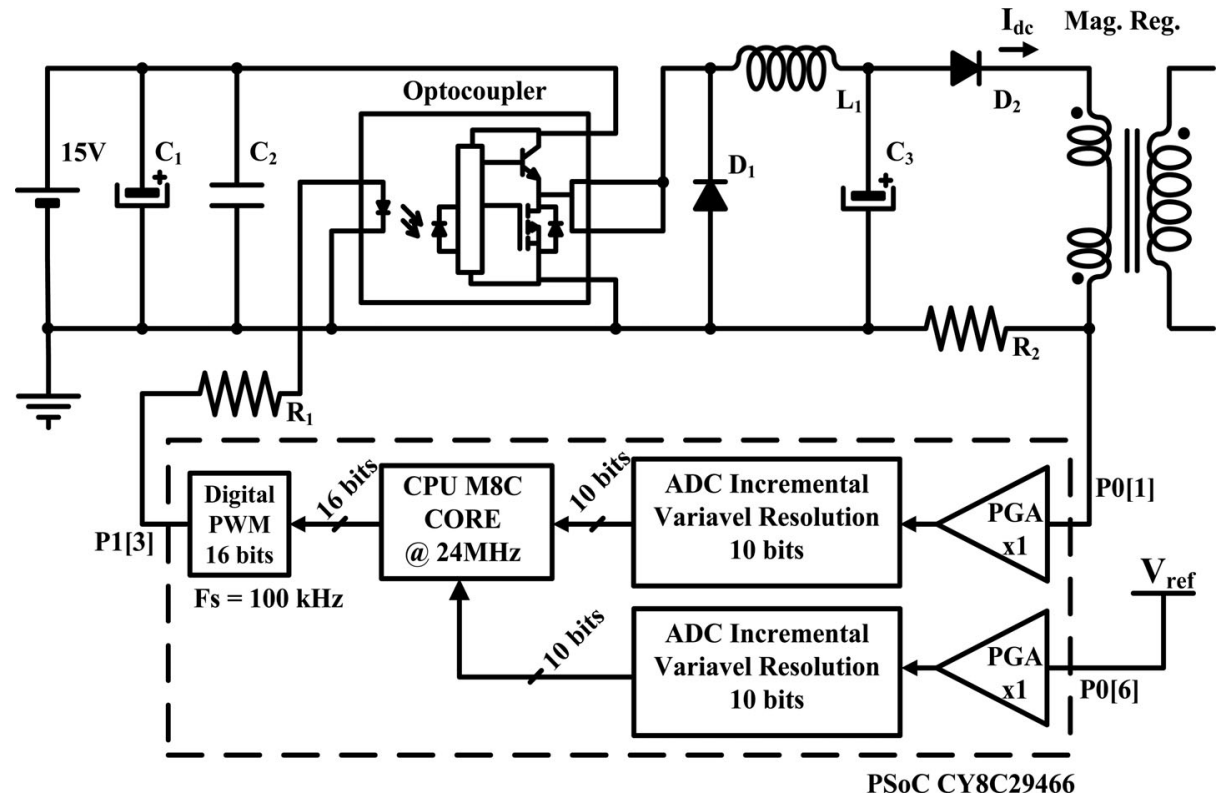

Fig. 12. Schematic of the dc-dc buck converter. 

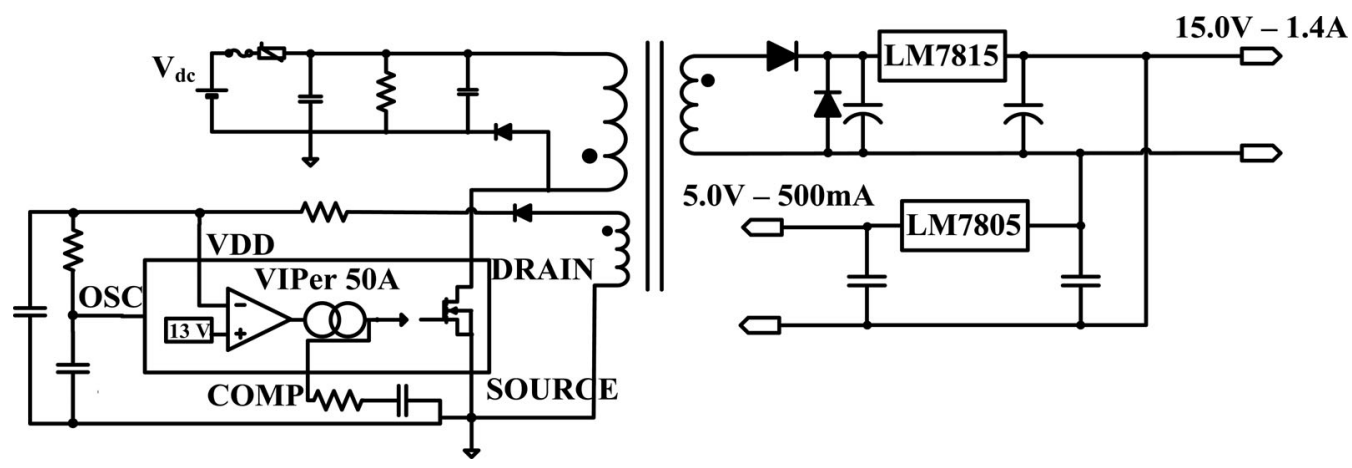

Fig. 13. Schematic of the flyback converter.
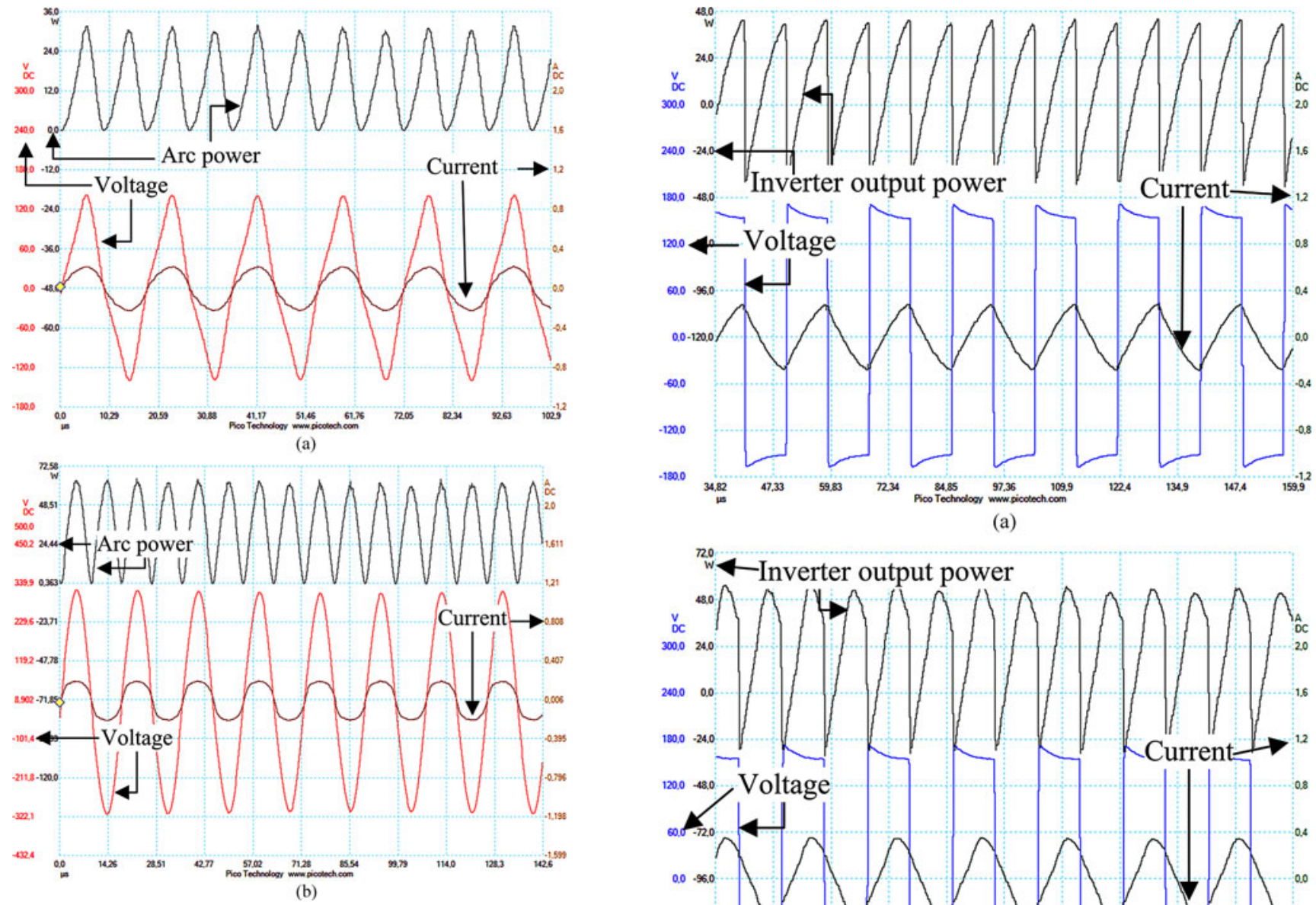

Fig. 14. Lamp voltage and arc current waveforms at rated power. (a) HE 14 W (12 W/div, $60 \mathrm{~V} / \mathrm{div}, 0.4 \mathrm{~A} / \mathrm{div}$, and $10.29 \mu \mathrm{s} / \mathrm{div})$. (b) HE $35 \mathrm{~W}$ ( $24.08 \mathrm{~W} / \mathrm{div}$, $110.3 \mathrm{~V} / \mathrm{div}, 0.4 \mathrm{~A} / \mathrm{div}$, and $14.26 \mu \mathrm{s} / \mathrm{div})$.

is based on the software tool provided by the manufacturer, ST Microelectronics, [33]. Fig. 13 shows the implemented flyback converter. An additional output of $5 \mathrm{~V}$ was considered in order to supply the voltage necessary for the microcontroller.

\section{EXPERIMENTAL RESULTS}

The data collected during prototype testing were retrieved with a picoscope. The magnetic regulator inductance was adjusted until both rms values of lamp voltage and arc current were

coherent with the values imposed by the manufacturer [12]. As shown in Table $\mathrm{V}$, the obtained values for all lamps are all within the limits imposed by the manufacturers. These limits were previously presented in Table III.

Fig. 15. Voltage and current at the input of the resonant tank. (a) HE 14 W (24 W/div, $60 \mathrm{~V} / \mathrm{div}, 0.4 \mathrm{~A} / \mathrm{div}$, and $12.54 \mu \mathrm{s} / \mathrm{div})$. (b) HE $35 \mathrm{~W}(24 \mathrm{~W} / \mathrm{div}$, $60 \mathrm{~V} / \mathrm{div}, 0.4 \mathrm{~A} / \mathrm{div}, 12.14 \mu \mathrm{s} / \mathrm{div})$ 


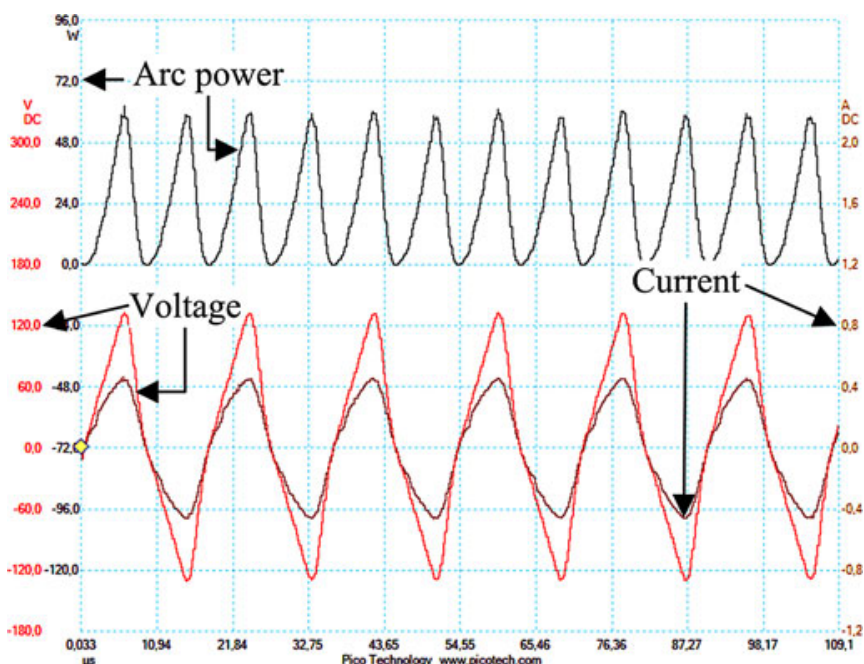

(a)

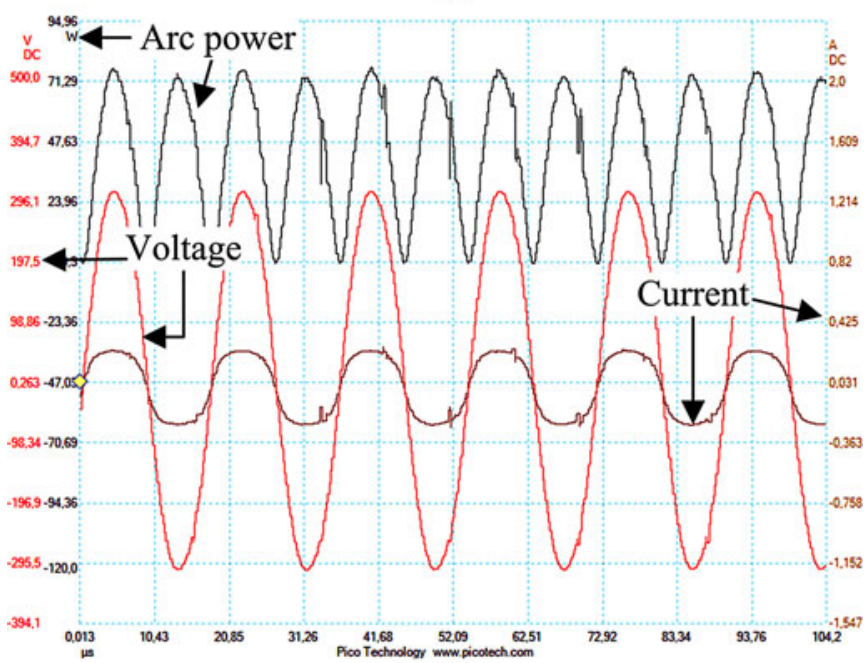

(b)

Fig. 16. Lamp voltage and current waveforms at rated power. (a) $\mathrm{HO} 24 \mathrm{~W}$ (24 W/div, $60 \mathrm{~V} / \mathrm{div}, 0.4 \mathrm{~A} / \mathrm{div}$, and $10.91 \mu \mathrm{s} / \mathrm{div})$. (b) HO $49 \mathrm{~W}(20.96 \mathrm{~W} / \mathrm{div}$, $98.6 \mathrm{~V} / \mathrm{div}, 0.394 \mathrm{~A} / \mathrm{div}$, and $10.42 \mu \mathrm{s} / \mathrm{div})$.

In order to verify if the lamps present a normal operating condition at steady state, the typical lamp voltage and arc current waveforms were analyzed. Fig. 14 shows the lamp voltage, arc current, and arc power waveforms for the TL5 HE $14 \mathrm{~W}$ and TL5 HE $35 \mathrm{~W}$ that represent the limits of the TL5 HE series. Fig. 15 shows the voltage, current, and power waveforms at the input of the resonant tank for the same lamps. As expected in Fig. 15(a), the resonant current waveform lags the inverter output voltage, so the circuit behaves as an inductive load, whereas Fig. 15(b) presents a resonant current with a near sinusoidal waveform, meaning that the circuit is near its resonance point. In all the conditions, the resonant current lags the inverter output voltage, meaning that ZVS operation is present in all of them.

Figs. 16 and 17 present similar waveforms for the TL5 HO $24 \mathrm{~W}$ and TL5 HO $49 \mathrm{~W}$. The same characteristics are present. For the $\mathrm{HO} 24 \mathrm{~W}$, the resonant circuit behaves as an inductive load, with its $Q$ factor less than 1, whereas for the $\mathrm{HO} 49 \mathrm{~W}$, the

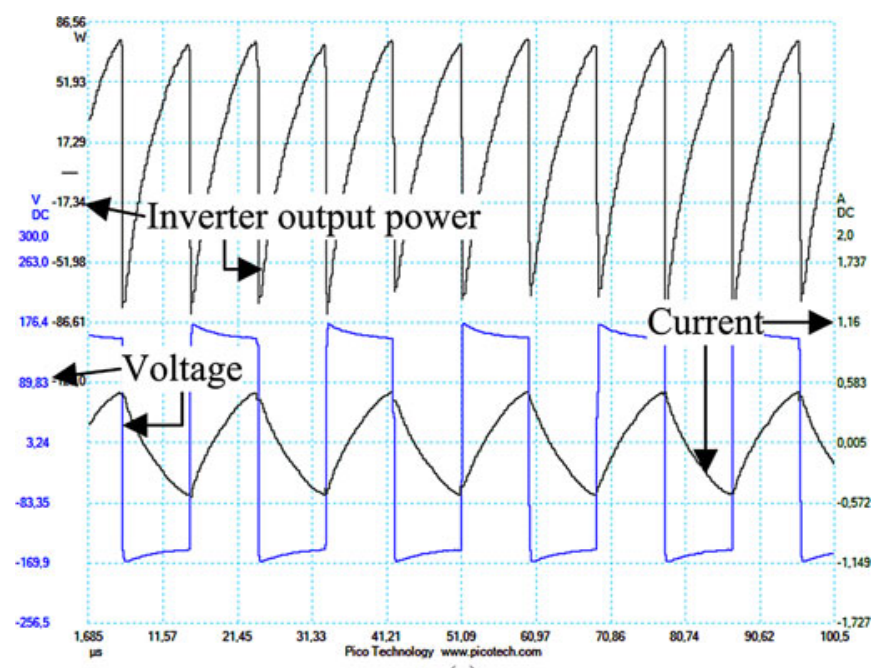

(a)

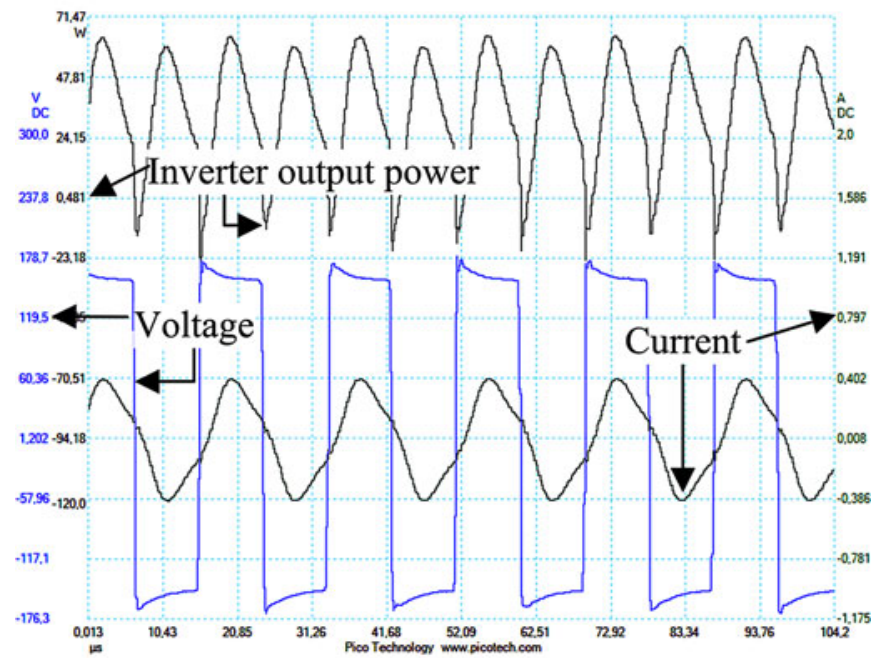

(b)

Fig. 17. Voltage and current at the input of the resonant tank. (a) HO $24 \mathrm{~W}(17.29 \mathrm{~W} / \mathrm{div}, 86.59 \mathrm{~V} / \mathrm{div}, 0.57 \mathrm{~A} / \mathrm{div}$, and $9.885 \mu \mathrm{s} / \mathrm{div})$. (b) $\mathrm{HO} 49 \mathrm{~W}$ (23.67 W/div, 59.16 V/div, $0.394 \mathrm{~A} / \mathrm{div}$, and $10.42 \mu \mathrm{s} / \mathrm{div})$.

circuit has a $Q$ factor greater than 1 and the resonant inverter output waveforms exhibit the expected behavior.

Table VI presents the power ratings achieved by each tested lamp with the prototype. The values presented were considered as follows: $P_{\text {lamp }}$ is the lamp power, given by the dc average value of the product between the lamp voltage and $I_{L H}$, which is also the resonant current; $P_{\text {arc }}$ is the discharge power or arc power, given by the dc average value of the product between the lamp voltage and the discharge current $I_{D} ; P_{\text {electr }}$ is the total power loss in the lamp electrodes, given by the dc average value of the product of the lamp electrode voltage by $I_{L H} ; P_{\text {global }}$ is the dc input power of the ballast, supplied by an external dc power source. The efficiency of the ballast is given by the ratio between $P_{\text {lamp }}$ and $P_{\text {global }}$ in percentage points. According to the achieved results, only the $\mathrm{HO} 49 \mathrm{~W}$ does not reach its nominal lamp power; however, it still operates at a value higher than the minimum power recommended by the manufacturer. Moreover, with the implemented prototype, a fine adjustment to 
TABLE VI

Power Rating of the Ballast and Tested Lamps, Large-Signal Inductance Values, and Control CuRRENT dC Values

\begin{tabular}{cccccccc}
\hline \hline Lamp & $\boldsymbol{P}_{\text {lamp }}[\mathbf{W}]$ & $\boldsymbol{P}_{\text {arc }}[\mathbf{W}]$ & $\boldsymbol{P}_{\text {electr }}[\mathbf{W}]$ & $\boldsymbol{P}_{\text {global }}[\mathbf{W}]$ & $\boldsymbol{\eta}[\%]$ & $\boldsymbol{L}_{\boldsymbol{a c}}[\mathbf{m H}]$ & Buck $\boldsymbol{I}_{\boldsymbol{d c}}[\mathbf{A}]$ \\
\hline \hline HE14W & 14.04 & 13.98 & 0.717 & 17.29 & 81 & 2.63 & 0.2283 \\
\hline HE21W & 21.36 & 21.09 & 1.217 & 23.59 & 91 & 2.35 & 0.2595 \\
\hline HE28W & 28.78 & 27.99 & 2.087 & 31.04 & 93 & 2.54 & 0.2565 \\
\hline HE35W & 36.02 & 34.65 & 2.740 & 38.25 & 94 & 2.68 & 0.2692 \\
\hline HO24W & 24.05 & 24.21 & 0.451 & 28.26 & 85 & 1.10 & 0.6548 \\
\hline HO39W & 38.74 & 38.95 & 0.438 & 44.43 & 87 & 0.96 & 0.7863 \\
\hline HO49W & 43.99 & 43.20 & 1.167 & 48.05 & 92 & 1.89 & 0.5234 \\
\hline \hline
\end{tabular}

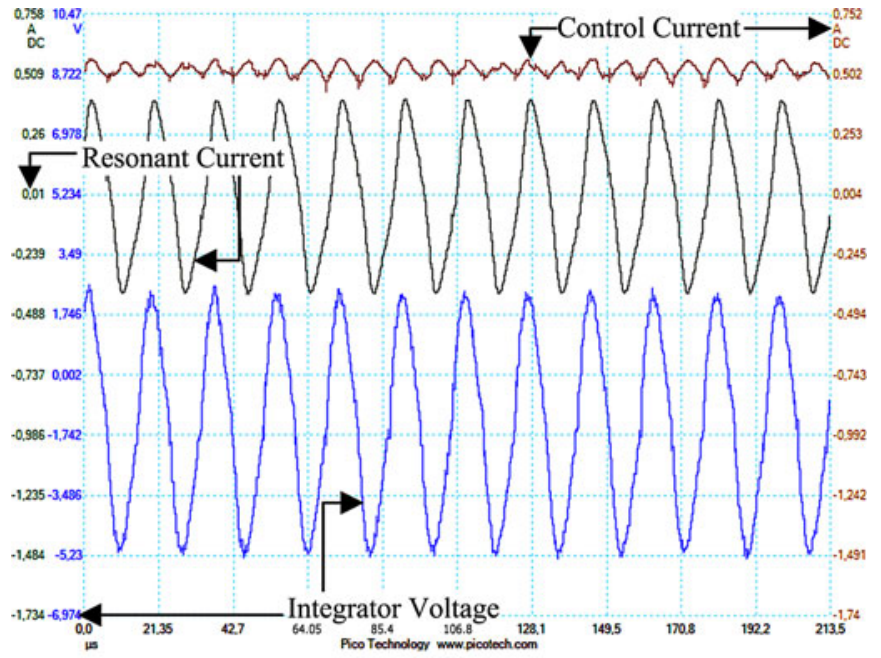

(a)

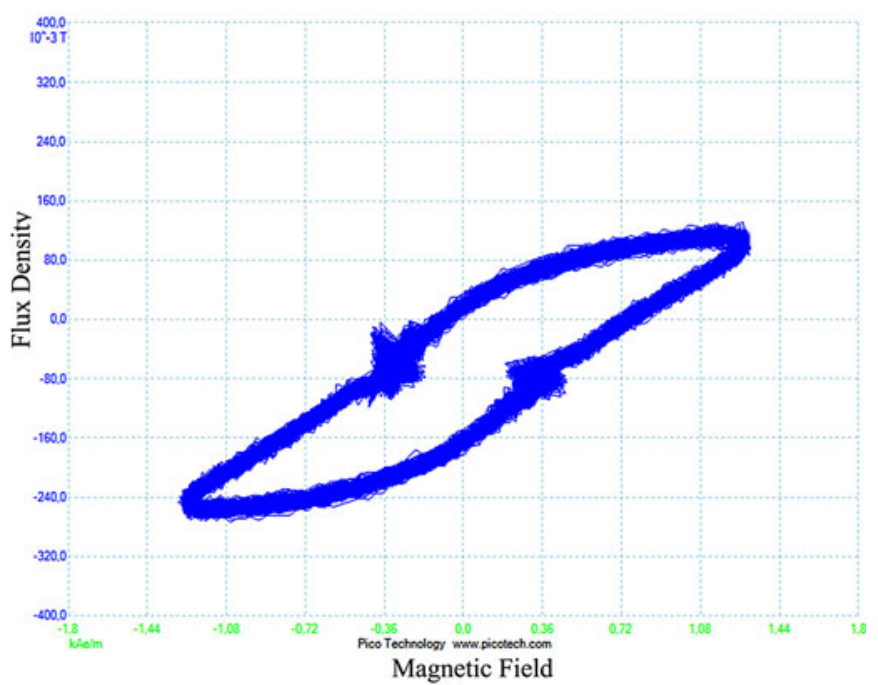

(b)

Fig. 18. HO 49 W. (a) Integrator voltage, resonant current, and control current waveforms at rated power $(1.744 \mathrm{~V} / \mathrm{div}, 0.25 \mathrm{~A} / \mathrm{div}, 0.249 \mathrm{~A} / \mathrm{div}$, and $21.35 \mu \mathrm{s} / \mathrm{div})$. (b) $B(H)$ curve of the magnetic regulator $(80 \mathrm{mT} / \mathrm{div}$ and 360 A.e. $\left.\mathrm{m}^{-1} / \mathrm{div}\right)$.

the inductance of the magnetic regulator would take $V_{\text {lamp }}$ over the maximum recommended voltage.

Table VI also presents the dc control current value dictated by the operation of the buck converter and the experimental largesignal inductance values for each attached lamp. These values

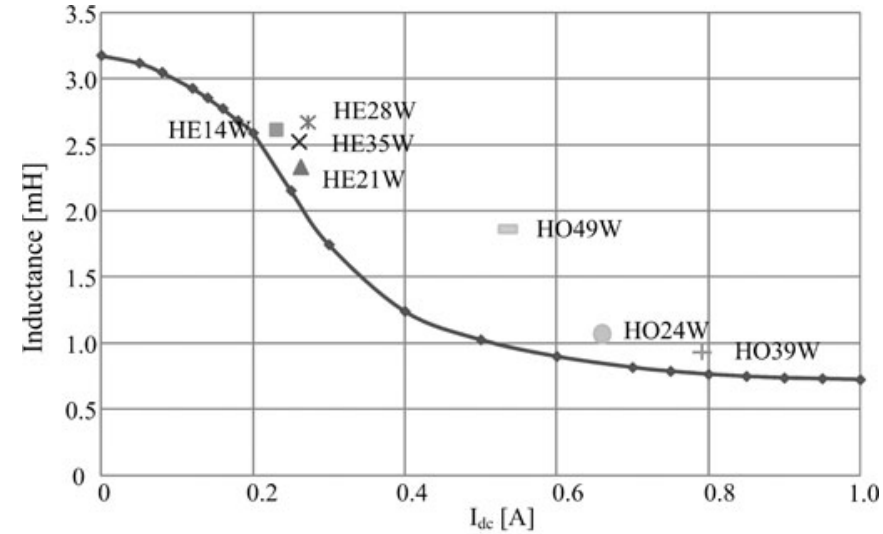

(a)

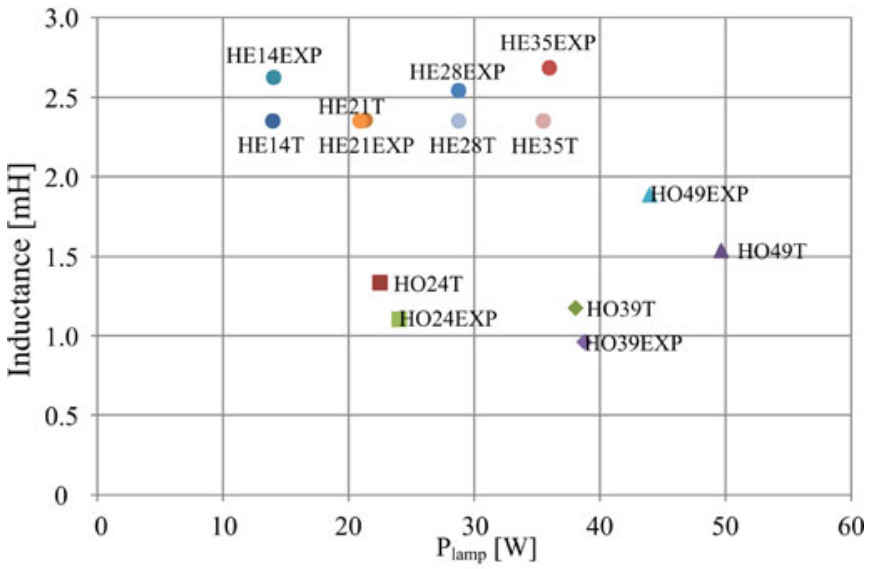

(b)

Fig. 19. (a) Small-signal and large-signal inductances as a function of the control current. (b) Comparison between theoretical and experimental inductance values for each lamp.

were obtained using

$$
L_{\text {ac }}=R \cdot C \cdot \frac{v_{c_{-} p p}}{i_{\text {res_pp }}}
$$

where $v_{c_{-} p p}$ is the peak-to-peak output voltage of the $R C$ integrator circuit and $i_{\text {res_pp }}$ is the peak-to-peak resonant current. The integrator circuit parameters are $R=100 \mathrm{k} \Omega$ and $C=2.2$ $\mathrm{nF}$. A detailed description for this method can be found in [32].

Fig. 18(a) presents the integrator voltage, the resonant current, and control current waveforms at rated power for the HO $49 \mathrm{~W}$, while Fig. 18(b) shows the typical $B(H)$ curve, characteristic 
of the magnetic regulator, which was used to determine the measured inductance as presented in Fig. 19. Once again, in these conditions, the magnetic regulator was supplying the lamp with the highest value of power.

Fig. 19(a) shows the magnetic regulator small-signal characteristic and the experimental large-signal inductance values $L_{\mathrm{ac}}$ for each tested lamp. These values are distributed according to the dc current value flowing through the control windings of the magnetic regulator, measured by the microcontroller. All values are approximately distributed along the presented characteristic. It should be noticed that only the HO $49 \mathrm{~W}$ lamp shows a significant difference. This can be explained by the fact that this lamp is not working exactly at rated power. In addition, the large-signal inductance values tend to be higher for the same dc control current value.

Fig. 19(b) shows the difference between theoretical and experimental results for estimated inductance values. This slightly different behavior was expected. The method that was used for determining the resonant circuit parameters is based on the fundamental approximation and the equations are defined assuming that the circuit is operating near resonance. However, some of the sets of fluorescent lamp plus filter are not in resonant mode and in those circumstances the resonant current will not assume a perfect sinusoidal waveform. This implies that the real inductance value required to operate each lamp at its rated power is expected to be slightly different.

\section{CONCLUSION}

This paper presents the development of a prototype for a universal electronic ballast for TL5 fluorescent lamps. The ballast was implemented using a resonant inverter with a constant switching frequency and a magnetic regulator. Results show that it was possible to achieve nominal power to nearly all the selected T5 lamps using only the variation of the resonant circuit inductance. Also, ZVS operation was verified for all tested lamps as shown in the presented experimental results. Each SoS limit was respected using a dual parallel capacitor configuration and a good performance was obtained for the entire prototype.

Even if these lamps can be identified by the analysis of the lamp voltage, a better solution to identify T12, T8, and T5 lamps has been proposed in [4]. Adapting this detection method to the presented prototype would represent an improvement. The possibility to extend the application to other lamp types may also be considered as option.

If a discrete set of operating frequencies together with the variable inductance are used as control parameters, the next obvious step would be to include dimming as a new feature in the prototype. In such case, the concern would be to design an EMI filter capable of dealing with this set of frequencies. However, even in these conditions, for each lamp, and using a similar magnetic control technique, the role of reducing the luminous flux level would only be dictated by the variable inductance. The prototype would actually work for each of these lamps at a constant operating frequency, thereby limiting the known problems dictated by frequency control.

\section{REFERENCES}

[1] J. C. W. Lam and P. K. Jain, "A novel high-power-factor single-switch electronic ballast," IEEE Trans. Ind. Appl., vol. 46, no. 6, pp. 2202-2211, Nov./Dec. 2010.

[2] Y.-T. Huang, H.-C. Hsiao, Y.-H. Liu, C.-R. Lee, and L.-L. Lee, "A novel constant-power control for metal-halide lamp electronic ballasts with dimming capability," IEEE Trans. Plasma Sci., vol. 38, no. 6, pp. 1482-1488, Jun. 2010.

[3] F. J. Diaz, F. J. Azcondo, C. Brañas, R. Casanueva, and R. Zane, "Digitally controlled low-frequency square-wave electronic ballast with resonant ignition and power loop," IEEE Trans. Ind. Appl., vol. 46, no. 6, pp. 2222 2232, Nov./Dec. 2010.

[4] L.-M. Lee and S. Y. Hui, "Automatic lamp detection and operation for warm-start tubular fluorescent lamps," IEEE Trans. Power Electron., vol. 24, no. 12, pp. 2933-2941, Dec. 2009.

[5] M. S. Perdigão, J. M. Alonso, M. A. D. Costa, and E. S. Saraiva, "Using magnetic regulators for the optimization of universal ballasts," IEEE Trans. Power Electron., vol. 23, no. 6, pp. 3126-3134, Nov. 2008.

[6] J. M. Alonso, M. S. Perdigao, J. Ribas, D. Gacio, and E. S. Saraiva, "Optimizing universal ballasts using magnetic regulators and digital control," IEEE Trans. Ind. Electron., vol. 58, no. 7, pp. 2860-2871, Jul. 2011.

[7] P. W. Tam, H. S.-H. Chung, and S. Hui, "Iterative behavioral modeling of charge-pump-based electronic ballast-fluorescent lamp system," IEEE Trans. Power Electron., vol. 24, no. 1, pp. 278-287, Jan. 2009.

[8] G.-C. Hsieh, "Group-asymmetrical PWM control for dimmable fluorescent lamp ballast without striation and thermostat effect," IEEE Trans. Power Electron., vol. 24, no. 5, pp. 1293-1303, May 2009.

[9] H. Wang, A. V. Stankovic, L. Nerone, and D. Kachmarik, "A novel discrete dimming ballast for linear fluorescent lamps," IEEE Trans. Power Electron., vol. 24, no. 6, pp. 1453-1462, Jun. 2009.

[10] N. Chen and H. S.-H. Chung, "A dimming module for controlling power supplying to a fluorescent lamp ballasted by a nondimmable electronic ballast," IEEE Trans. Power Electron., vol. 25, no. 10, pp. 2541-2551, Oct. 2010.

[11] M. K. Kazimierczuk and D. Czarkowski, Resonant Power Converters. New York: Wiley, 1995, ch. 7.

[12] Philips Lighting B.V., Philips MASTER TL5 lamps, Datasheet, 2006.

[13] GE Lighting, T5 Long Last, linear fluorescent lamps, Datasheet, Apr. 2009.

[14] R. Seidel, M. Polonskii, R. A. Eichelberger, J. C. A. Rigo, and T. M. Rodegheri, "Designing dimmable electronic ballasts with frequency control," in Proc. Ninth Brazilian Power Electron. Conf., COBEP 07, Blumenau, SC, Brazil, 2007, pp. 91-96.

[15] L. H. Goud and J. W. F. Dorleijn, "Standardized data for dimming of fluorescent lamps," in Proc. 37th Ind. Appl. Soc. Annu. Meet. Conf. Rec. Ind. Appl. Conf., 2002, vol. 1, pp. 673-679.

[16] R. Nachtrieb, F. Khan, and J. F. Waymouth, "Cathode fall measurements in fluorescent lamps," J. Phys. D: Appl. Phys., vol. 38, pp. 3226-3236, Aug. 2005.

[17] A. Bogdan, "Programmable universal lighting system," U.S. Patent 6040 661, Mar. 21, 2000.

[18] S. Y. R. Hui, and L. M. Lee, "Universal electronic ballast," U.S. Patent 6 414 449, Jul. 2, 2002.

[19] L. M. Lee, S. Y. R. Hui, and H. S. H. Chung, "An automatic lamp detection technique for electronic ballasts," in Proc. 20th Annu. IEEE Appl. Power Electron. Conf. Expo., 2005, vol. 1, pp. 575-581.

[20] P. N. N. Ayudhya, S. Naetiladdanon, and A. Sangswang, "Automatic fluorescent lamp detection technique for electronic ballasts," in Proc. IEEE Int. Conf. Robot. Biomimetics, Feb. 2009, vol. 1, pp. 1047-1052.

[21] P. N. N. Ayudhya, S. Naetiladdanon, and A. Sangswang, "Automatic fluorescent lamp detection for electronic ballasts based on operating frequency and phase shift compensation," IEEE Int. Symp. Ind. Electron., vol. 1, pp. 53-58, Jul. 2009.

[22] J. M. Alonso, M. A. D. Costa, J. Cardesín, J. García, and M. Rico-Secades, "A new control method for electronic ballasts based on magnetic regulators," in Proc. 40th Ind. Appl. Soc. Annu. Meet. Conf. Rec. Ind. Appl. Conf., Oct. 2005, vol. 3, pp. 1958-1964.

[23] J. M. Alonso, M. A. D. Costa, J. Cardesín, and J. García;, "Magnetic dimming of electronic ballasts," Electron. Lett., vol. 41, no. 12, pp. 718718, Jun. 2005.

[24] S. Borekci and S. Oncu, "Dimming self-oscillating ballast by variable inductor," Electron. Lett., vol. 43, no. 14, pp. 772-774, Jul. 2007.

[25] J. M. Alonso, M. S. Perdigao, D. Gacio, L. Campa, and E. S. Saraiva, "Magnetic control of DC-DC resonant converters provides constant frequency operation," Electron. Lett., vol. 46, no. 6, pp. 440-442, 2010. 
[26] R. D. Washburn and R. F. McClanahan, "Non-saturating magnetic amplifier controller," US Patent 4841 428, Jun. 20, 1989.

[27] J. Vollin, F. D. Tan, and S. M. Cuk, "Magnetic regulator modeling," in Proc. 8th Annu. IEEE Appl. Power Electron. Conf. Expo., 1993, pp. 604-611.

[28] D. Medini and S. Ben-Yaakov, "A current-controlled variable inductor for high frequency resonant power circuits," in Proc. IEEE Appl. Power Electron. Conf., 1994, pp. 219-225.

[29] E. Orietti, P. Mattavelli, G. Spiazzi, C. Adragna, and G. Gattavari, "Twophase interleaved LLC resonant converter with current-controlled inductor," in Proc Brazilian Power Electron. Conf., Sep. 27-Oct. 1, 2009, pp. 298-304.

[30] Y. Hu, L. Huber, and M. M. Jovanovic, "Universal-input single-stage PFC flyback with variable boost inductance for high-brightness LED applications," in Proc. IEEE Twenty-Fifth Annual, Applied Power Electron. Conf. Expo. (APEC),, Feb. 21-25, 2010, pp. 203-209.

[31] J. M. Alonso, Power Electronics Handbook, M. H. Rashid, Ed., New York: Academic, 2001, ch. 21.

[32] M. S. Perdigão, B. Baptista, J. M. Alonso, and E. S. Saraiva, "Magnetic regulator topologies for dimmable electronic ballasts," in Proc. IEEE Int. Symp. Ind. Electron., 2010, pp. 921-926.

[33] ST Microelectronics. (2010, Sep.). VIPer flyback converter design [Online]. Available: www.st.com

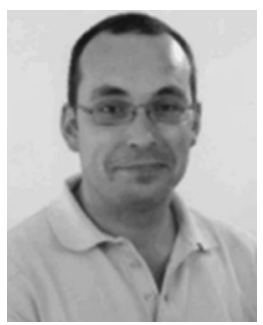

H. V. Marques was born in Avelar, Portugal, in 1983. $\mathrm{He}$ received the M.Sc. degree in electrical engineering from the University of Coimbra, Coimbra, Portugal, in 2010.

Since 2010, he has been a Researcher at the Instituto de Telecomunicações, Universidade de Coimbra. His research interests include high-frequency electronic ballasts, high-frequency switching converters, resonant converters, power electronics, microcontrollers, and computer simulation applications.

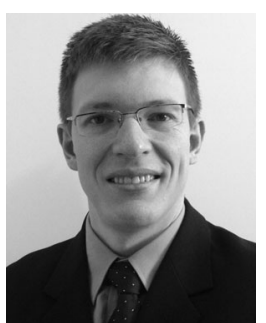

Álysson R. Seidel (M’03) was born in São Pedro do Sul, Brazil, in 1975. He received the B.S. and Ph.D. degrees in electrical engineering from the Federal University of Santa Maria, Santa Maria, Brazil, in 1999 and 2004, respectively.

From 2004 to 2008, he was an Associate Professor in the Department of Electrical Engineering, University of Passo Fundo, Passo Fundo, Brazil. He is currently at the Federal University of Santa Maria, where he has been a Professor at the Colégio Técnico Industrial de Santa Maria and a Researcher in the Electronic Ballast Research Group since 1997 and the Electrical and Computational Systems Research and Development Group since 2010. His research interests include resonant converters, dimming systems, simulation, discharge lamps, and lighting systems.

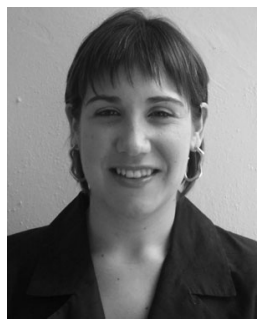

Marina S. Perdigão (S'06) was born in Coimbra, Portugal, in 1978. She received the M.Sc. degree in electrical engineering from the University of Coimbra, Coimbra, in 2004. She has been working toward the Ph.D. degree from the University of Coimbra in cooperation with the University of Oviedo, Oviedo, Spain, since 2006

Since 2002, she has been an Assistant Professor in the Department of Electrical Engineering, Superior Institute of Engineering of Coimbra, Coimbra. Since 2001, she has also been a Researcher at the Instituto de Telecomunicações, Coimbra. Her research interests include high-frequency electronic ballasts, discharge lamp modeling, high-frequency switching converters, resonant converters, power electronics for renewable energies, and computer simulation applications.

Ms. Perdigão received the Best Paper Award of the 2009 IEEE International Symposium on Industrial Electronics. She also collaborates as an IEEE Transactions Paper Reviewer.

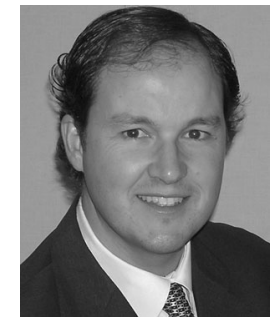

J. Marcos Alonso (S'94-M'98-SM'03) received the M.Sc. and Ph.D. degrees in electrical engineering from the University of Oviedo, Oviedo, Spain, in 1990 and 1994, respectively.

Since 2007, he has been a Full Professor in the Department of Electrical and Electronics Engineering, University of Oviedo, Gijón, Spain, where he was an Assistant Professor from 1990 to 1999, and an Associate Professor from 1999 to 2007. He is the author more than 70 journal and international conference papers in power and industrial electronics, and has coauthored more than 200. He was the advisor to six Ph.D. theses in the field of power electronics. He is the holder of six Spanish patents. His research interests include high-frequency electronic ballasts, discharge lamp modeling, power converters for ozone generation, power converters for electrostatic applications, power factor correction topologies, and high-frequency switching converters in general

Dr. Alonso has been awarded national funding for the Intensification of Research Activity during the time period of 2008-2012. He was awarded the Early Career Award of the IEEE Industrial Electronics Society in 2006. $\mathrm{He}$ received the Best Paper Award of the 2009 IEEE International Symposium on Industrial Electronics, the second Prize Paper Award of the 2005 IEEE Industry Applications Society Meeting, Production and Application of Light Committee, and the IEEE Industrial Electronics Society Meritorious Paper Award in 1996. He is an active member of the IEEE, where he collaborates as Transactions Paper Reviewer, Conference Session Chairman, Session Organizer, among other positions. Since October 2002, he been an Associate Editor of the IEEE TRANSACTIONS ON POWER ELECTRONICS in the field of lighting applications. He served as a Guest Editor for the Special Issue on Lighting Applications, published in IEEE TRANSACTIONS ON POWER ELECTRONICS in May 2007. He is a member of the European Power Electronics Association and he belongs to the International Steering Committee of the European Conference on Power Electronics and Applications, where he collaborates as Topic Co-Chair. He is a member of the International Ozone Association.

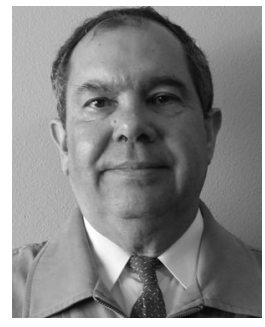

E. Sousa Saraiva (M'79) received the Lic degree in electrical engineering from the University of Oporto, Oporto, Portugal in 1970, and the Ph.D. degree in electrical engineering from the University of London, London, U.K., in 1979. The aggregation in electrical engineering was received from the University of Coimbra, Coimbra, Portugal, in 1985.

He served on the Faculty of Science and Technology, University of Coimbra, as an Assistant Eventual from July 13, 1973 to July 12, 1975, as an Assistant from July 13, 1975 to July 24, 1979, as an Auxiliary Professor from July 25, 1979 to November 30, 1979, as an Associated Professor from December 01, 1979 to November 20, 1986, and as a Full Professor from November 21, 1986 to July 31, 2011. He retired on August 1, 2011. He is the coauthor of more than 100 papers in national and international journals and conferences. He was the adviser of 12 postgraduate students, coadviser of another, and currently a coadviser of one Ph.D. student and coadviser of a M.Sc. student. His research interests include electric machines, power electronics, the influence of the electromagnetic field in the human body, and, more recently, electronic ballasts for fluorescent lamps.

Dr. Saraiva has been a member of the IEEE for more than 25 years and collaborates as a Reviewer. He is one of the founders of the IEEE Portugal Section. $\mathrm{He}$ is a member of the Portuguese "Ordem dos Engenheiros," having in the past, been elected to positions in the Central Region and on National Boards. 